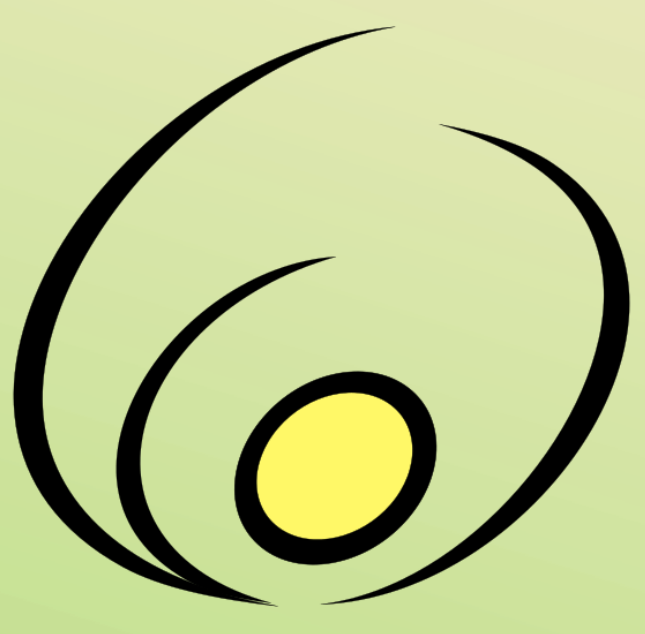

Fórum de

\section{Pró-Reitores}

\section{de Extensão}

\section{das Instituições}

\section{Públicas de}

\section{Educação Superior}

Brasileiras
Revista Brasileira de Extensão Universitária

v. 10, n. 3, p. 141-147, set.-dez. 2019 e-ISSN 2358-0399

DOI: https://doi.org/10.24317/2358-0399.2019v10i3.10840

Originais recebidos em 08 de abril de 2019

Aceito para publicação em 21 de outubro de 2019

\title{
A FORMAÇÃO CONTINUADA DE PROFESSORES DE CIÊNCIAS: ELEMENTOS CONSTITUTIVOS DO PROCESSO
}

\author{
Vanessa Aina Person ${ }^{1}$, Daniele Bremm², \\ Roque Ismael da Costa Güllich³
}

Resumo: Este texto tem como objetivo discutir os elementos constitutivos presentes no processo de formação continuada, buscando abordar particularmente alguns dos principais processos desenvolvidos, na tentativa de compreendê-los como aspectos importantes da formação em Ciências. Assim, passamos a analisar como o diálogo passa a constituir os sujeitos professores em formação, que partilham um ambiente coletivo e colaborativo. Neste sentido, torna-se uma categoria indispensável à formação. Os movimentos formativos desencadeados no Grupo de Estudos e Pesquisa em Ensino de Ciências e Matemática (GEPECIEM), por meio do projeto de extensão Ciclos Formativos no Ensino de Ciências, nos permitiram reconhecer a relevância de elementos que se tornam formativo-constitutivos do processo de formação de professores. Entre eles, podemos citar o diálogo formativo, o espelhamento de práticas, a sistematização de experiências, e as escritas narrativas reflexivas, compondo o modelo em defesa: Investigação-Formação-Ação.

Palavras-chave: Investigação-formação-ação; Ensino de ciências; Diálogo formativo

1 Universidade Regional do Noroeste do Estado do Rio Grande do Sul - UNIJUÍ. Mestre em Educação nas Ciências. vaynaperson@hotmail.com

2 Universidade Federal da Fronteira Sul - UFFS. Bolsista do Programa de Educação Tutorial PETCiências SESu - FNDE/MEC. bremmdaniele@gmail.com (autora para correspondência).

3 Universidade Federal da Fronteira Sul - UFFS. Doutor em Educação nas Ciências, Tutor do PETCiências. bioroque.girua@gmail.com 


\title{
Continuing education of science teachers: constituent elements of the process
}

\begin{abstract}
This text aims to discuss the constituent elements present in the process of continuous training, seeking to address individually some of the main processes employed in the attempt to understand them as important elements of the formation in Sciences. Thus, we begin to discuss how the dialogue constitutes the teachers as subjects in formation, who share a collective and collaborative environment. In this sense, it becomes an indispensable category to the formation. The formative movement was initiated by the Study and Research Group in Science and Mathematics Education (Grupo de Estudos e Pesquisa em Ensino de Ciências e Matemática - GEPECIEM) through the Extension Project 'Formative Cycles in Science Education', which allowed us to recognize the importance of elements that become formative-constitutive of the teacher training process. Among them, we can mention the formative dialogue, the systematization of experiences, and the reflexive narrative writings, which composing the model in defense: ResearchTraining-Action.
\end{abstract}

Keywords: Research-training-action; Science teaching; Formative dialogue

\section{La formación permanente del profesorado de ciencias: elementos constitutivos del proceso}

Resumen: Este texto tiene como objetivo discutir los elementos constitutivos presentes en el proceso de formación permanente, buscando enfocar especialmente algunos de los principales procesos desarrollados, en el intento de comprenderlos como aspectos importantes de la formación en Ciencias. Luego, pasamos a analizar como el diálogo pasa a constituir los sujetos y a conducir a la reflexión de profesores en formación, que comparten un ambiente colectivo y colaborativo y, por consiguiente, se convierte en una categoría indispensable para la formación. Los movimientos formativos desencadenados en el Grupo de Estudios y Pesquisa en Enseñanza de Ciencias y Matemáticas (GEPECIEM), a través del proyecto de Extensión 'Ciclos Formativos en la Enseñanza de Ciencias', nos permitieron reconocer la relevancia de principios que se convierten formativo-constitutivos del proceso de formación del profesorado. Entre ellos, podemos citar el diálogo formativo, el reflejo de prácticas, la sistematización de experiencias y los escritos narrativos reflexivos, componiendo el modelo en defensa: Investigación-Formación-Acción.

Palabras-clave: Investigación-formación-acción; Enseñanza de Ciencias; Diálogo Formativo

\section{Introdução}

A formação continuada de professores de Ciências desenvolvida pelo projeto de extensão: Ciclos Formativos no Ensino de Ciências e Matemática ${ }^{1}$ na Universidade Federal da Fronteira Sul, Campus Cerro Largo - RS, Brasil, busca formações inicial e continuada pautadas na racionalidade prática, que implica pensar uma formação através do modelo da Investigação-ação (IA). Este projeto de extensão almeja a indissociabilidade entre pesquisa, ensino e extensão. Neste sentido, além dos professores participarem do projeto, tornam-se também pesquisadores ativos no processo de IA.

O processo de formação continuada que investigamos segue a ideia da tríade de interação, conceito desenvolvido por Zanon (2003), ou modelo de pesquisa compartilhada, que ocorre entre professores formadores, professores de escola básica e licenciandos. Deste contexto, depreendemos a ideia de professores em formação como uma categoria de que todos participam com vez e voz. Em tese, este é um dos princípios da IA crítica, defendia por Carr e Kemmis (1988).
Os movimentos formativos desencadeados por este projeto de extensão permitiram-nos reconhecer a importância de elementos que se tornam formativoconstitutivos do processo de formação de professores, em especial acerca da formação continuada. Assim, buscamos investigar o modelo e os processos de formação de professores a partir de referenciais teórico-metodológicos da IA crítica (CARR; KEMMIS, 1988; ALARCÃO, 2010; GÜLLICH, 2013) como forma de compreendê-los. Este texto tem o objetivo de discutir os elementos constitutivos presentes no processo de formação continuada do contexto descrito, buscando abordar individualmente alguns dos principais processos empregados, na tentativa de compreendê-los como elementos importantes da formação em Ciências.

\section{Metodologia}

Os processos formativos, desencadeados pelo desenvolvimento dos ciclos formativos, geraram inúmeros dados passíveis de análise e construções reflexivas de pesquisa. A coleta de dados foi direcionada aos encontros 
de formação deste projeto, os quais, desde o ano de 2010, foram gravados em áudio, transcritos e analisados por pesquisadores da área de educação em Ciências da UFFS (KIEREPKA; GÜLLICH, 2013; PERSON; BOSZKO; GÜLLICH, 2015; PERSON; GÜLLICH, 2015a, 2015b, 2015c; 2015d); também foram analisadas as narrativas nos diários de formação dos participantes. Cabe destacar que, a partir de 2011, todos os sujeitos que participavam do grupo iniciaram o desenvolvimento de escritas narrativas nos diários de formação.

Analisamos os encontros desencadeados nos ciclos formativos, os quais partem das diferentes experiências dos sujeitos, dando ênfase aos diálogos formativos que principiam, e à reflexão dos sujeitos envolvidos. Deste contexto, depreendemos nossos entendimentos teóricopráticos, aqui expressos e defendidos como elementos de formação/constituição docente em Ciências. Acreditamos que o diálogo é um indício de que a reflexão começa a ser efetivada no processo formativo e, desta forma, caracteriza certo desenvolvimento em relação ao modelo de IA. Assim, discutimos como o diálogo passa a constituir os sujeitos e a adensar a reflexão de professores em formação que partilham um ambiente coletivo e colaborativo.

\section{Resultados: os elementos constituintes de um processo de formação de professores}

A despeito dos modelos de formação, sabemos que muito do que se tinha em termos de formação através de cursos de curta duração, voltados à atualização e/ou a ensinar diferentes metodologias de ensino, continuam sendo propagados nos tempos atuais (CARVALHO; GILPÉREZ, 2001). Porém, com o avanço de pesquisas educacionais e o surgimento da prática como racionalidade possível de empreender outros modelos de formação, os processos formativos que partem dos contextos práticos, das vivências docentes, tem como propulsora a IA (NÓVOA, 1995).

O diálogo formativo passa a ser um elemento essencial na formação continuada de professores de Ciências, pois é através dele que se desencadeiam as interações entre os sujeitos, assumindo um papel importantíssimo. Alarcão (2010, p. 49) nos aponta que podemos encontrar um triplo diálogo: “[...] um diálogo consigo próprio, um diálogo com os outros, incluindo os que antes de nós construíram conhecimentos que são referência, e o diálogo com a própria situação".

Podemos citar como exemplo um recorte de um encontro de formação do ano de 2011, em que é notório como a interação entre os professores desencadeia a formação compartilhada. Observamos que o diálogo passa do nível meramente descritivo a um nível explicativo e crítico, que permite aos profissionais do ensino agir e falar com o poder da razão.

T1: Bom, eu fiz por escrito, mas algumas coisas aqui eu não escrevi, não é? Agora vi as conclusões dos alunos no relatório final, algumas coisas eu devia ter colocado e não coloquei. Então assim esta aula que eu fiz foi sobre classificação taxonômica dos seres vivos, na sexta série. Dai eu coloquei assim: relato de experiência. $O$ presente relato descreve uma aula prática de Ciências na sexta série do ensino fundamental sobre a classificação taxonômica que é dos seres vivos. [...] Nesse sentido, após a teoria sobre a importância de classificar, separar em grupos e relacionar seres vivos de acordo com certas características fisiológicas $e$ morfológicas, partimos para a prática. [...] A solicitação foi que cada grupo discutisse entre seus integrantes uma forma de agrupar obedecendo a determinados critérios conforme seus conceitos prévios [...] Sendo assim, emergiram diversas maneiras de classificação como pela forma do corpo, nutrição, hábitat, etc. e com isso os alunos puderam compreender um pouco do procedimento científico. [...] A aula foi dinâmica e divertida, pois os alunos além de interagir, trocaram ideias, questionamentos e refletiram sobre a importância de conhecer e registrar as diferentes espécies de seres vivos existentes na terra (Professora 1).

[...] T2: Eu senti assim, é uma coisa que a gente vê mesmo quando a gente trabalhar isso aqui sem essa prática da visualização, a compreensão é bem diferente do que com a prática que você fez, porque o envolvimento, a empolgação deles, a vibração, a participação foi incrível [...] me chamou a atenção isso de ver eles com esse material separando, eu acho assim a fixação desse conteúdo pode ser para sempre através dessa prática (Professora 3 ).

T3: Para eles se torna significativo, até então chegar lá, passar o conteúdo e dar aquele monte de classificação é horrível. Para ele não significa nada, $e$ daí não entende [...] eu olhei a prática da Professora 1, eles assim assumem uma postura não é Professora 1?(Professora 10).

T4: Aham (Professora 1).

T5: E daí e todos participam. Isso é muito significativo (Professora 10).

T6: Eu gostei dessa técnica. [...] me chamou atenção sabe o que? Também que na hora da avaliação eu fiz uma provinha no fim com todo o conteúdo. Acho que não teve um que não acertou o que era classificar, agrupar, separar de acordo com as características. Ótimo, sabe esse encontro (Professora 1). [...]

Após analisar as falas dos sujeitos, percebemos que o diálogo formativo avança pela recorrência entre citações referindo-se à prática de outrem, e as professoras envolvidas na discussão contribuem no relato da Professora 1. O jogo de falas possibilitado pelo diálogo formativo, com perguntas e respostas (GÜLLICH, 2013), ficou visível no episódio acima. Este movimento desencadeia uma discussão crítica acerca da prática da Professora 1, culminando em um momento de formação mútua, em que a reflexão coletiva favorece a ressignificação da prática da Professora 1, mas também das demais professoras, que se enxergam na prática relatada. Para que o diálogo se torne formativo, é necessário que haja o triplo diálogo, o qual, conforme descrito por Alarcão (2010), é um diálogo consigo próprio, com os outros do discurso(teóricos) e com a sua prática, bem como se faz necessária a colaboração de 
todos para a co-produção de conhecimentos (KIEREPKA; GÜLLICH, 2016).

Deste modo, é importante salientar que a sistematização de práticas, a partir do relato e diálogo sobre as experiências no grupo, é indispensável neste modelo de formação, pois na recorrência e recursividade das falas podemos evidenciar que a reflexão vai sendo desencadeada pelo diálogo formativo do grupo (GÜLLICH, 2013).

Outro modelo que julgamos essencial para que ocorra o diálogo formativo é o processo de espelhamento de práticas. Através deste elemento de formação, os participantes são desafiados a se distanciar de suas práticas pedagógicas e se aproximar das práticas de outrem para, no espelhamento, exporem seus pensamentos. Ao passo que refletem e põem em pauta seus dilemas docentes, assumem distintos modos de ver sua formação e sua docência.

Sempre que trazemos para a discussão situações homólogas àquelas vivenciadas pelos professores, estamos estabelecendo vínculos entre situações que coincidem com a realidade. Este processo é denominado "sala de espelhos" (SCHÖN, 1992). Ademais, Silva e Schnetzler nos explicam:

Assim, o profissional pode 'ver de fora', distanciando-se da situação, o que anteriormente havia vivenciado dentro de sua própria experiência. Dessa maneira, a análise que o profissional/professor faz da situação homóloga permite-lhe visualizar aspectos problemáticos da sua prática que podem tornar-se objeto de reflexão individual e coletiva (2000, p. 52).

Destacamos um exemplo de espelhamento de práticas $^{2}$ que ocorreu após a leitura do texto "Educar pela Pesquisa: exercício de aprender a aprender" (MORAES, 2012). Este texto narra histórias de aulas da segunda e da quinta séries do ensino fundamental e de um curso superior de formação de professores de Ciências:

[...] T3: Eu estava discutindo com a Professora Formadora 7 aqui, quando a Professora Formadora 6 falava, e ouvindo assim as colocações mais ai na parte de Ciências, quando, por exemplo, o tema é a genética, e ai o professor vai chegar à sala e vai perguntar o que é genética?[...] $E$ eu estou pensando isso na Matemática [...] Ai, eu me questionava assim, bom eu vou pensar que eu estou em uma turma de quinta série ou sexto ano, e que eu preciso começar a trabalhar frações ou números racionais, e que a pergunta jamais vai ser essa, o que vocês querem trabalhar sobre frações? [...] ai quando vocês falavam eu estava pensando, tá, e na Matemática como é que eu vou fazer isso?[...] Então para tentar trazer um pouquinho o que a gente já havia discutido da Matemática e como que de repente eu posso estar pensando na Matemática inserida nisso (Professora Formadora 3).

T4: Quando eu trabalhei frações na quinta série, eu trabalhei em sala de aula e fui para a prática, no colégio tinha areia, um monte de areia, daí nós pegava latinhas, pedia para eles trazer latinhas de azeite, ou de tamanhos diferentes, agora nós vamos ver o que é, por exemplo, um meio, na prática, dois terços, três terços, e nunca mais eles esqueciam as frações, a importância no dia a dia. Um aluno de Matemática, ele quer saber qual é disso aqui no meu dia a dia, onde eu vou usar isso? Aonde nós vamos usar as frações no nosso dia a dia, desde fazer um bolo, as receitas, nós trabalhávamos as receitas, eles traziam de casa, pegávamos água e dividia em partes diferentes, e assim foi maravilhoso trabalhar frações (Professora 3). [...]

Destacamos o espelhamento de práticas porque favorece o processo de IA e está ligado à resolução de problemas práticos. O diálogo formativo é precursor da reflexão, pois no diálogo entre os pares surgem questões, as quais suscitam uma reflexão formativa (GÜLLICH, 2013). A reflexão, quando em processos de formação de professores, torna-se uma categoria formativa, pois expande o conceito de IA para Investigação-FormaçãoAção (IFA).

Entendemos, como processo de Sistematização de Experiências encontros de formação em que os professores são postos a discutir práticas relatadas por outros colegas. Previamente um participante deverá relatar uma escrita já sistematizada que partiu de uma vivência sua, preferencialmente descrita em diário de formação, como uma prática docente. Apresentamos a seguir um episódio ${ }^{3}$ que decorreu da leitura da prática narrada no diário de formação de uma professora de Ciências e as discussões geradas a partir da prática relatada:

[...] T2: Hoje vamos realizar uma aula prática sobre fungos com o objetivo de demonstrar aos alunos a importância desses organismos para os outros seres vivos, desmistificando a ideia de que todos os fungos são parasitas e prejudiciais ao ambiente em que vivem. Para começar recebemos os alunos $e$ acomodamos os alunos no laboratório e pedimos que pegassem o caderno e uma caneta para fazer as devidas anotações. [...] com o roteiro em mãos, partimos para a prática que ocorreu de forma demonstrativa, pois essa turma é muito grande (33 alunos) e dispersa, e também os recursos são limitados, o que inviabilizou que os alunos montassem seus próprios experimentos. [...] quando eu a bolsista Licencianda 18, comentávamos que os resultados poderiam ter sido mais evidentes se não estivéssemos sido surpreendidas por uma queda na temperatura, o que acreditamos que prejudicou um pouco o processo de fermentação. [...] na aula seguinte um pouco mais da metade da turma entregou o relatório, o que já era de se esperar dessa turma, mas mesmo assim fiquei frustrada, pois espero o dia que a maioria da turma faça as atividades propostas e com dedicação. [...] percebo, a cada dia que passa que apesar dos problemas os alunos estão evoluindo, principalmente por causa das aulas práticas, que eles gostam muito e estão se tornando cada vez mais presentes [...] (Professora 18).

T3: Você já tinha trabalho sobre fungos anteriormente ou você começou esse assunto com essa aula prática?(Licencianda 19).

T4: Não, nós trabalhamos anteriormente já (Professora 18).

T5: Todos os alunos participaram?(Licencianda 12). 
T6: Sim, todos eles fizeram observações, tocaram nas garrafinhas, anotaram, mas o problema deles foi mesmo na hora que cada um foi construir o seu relatório. Tem alunos que não fazem (Professora 18). [...]

Da leitura e análise dos episódios é possível depreender a interação entre professoras da escola básica, licenciandos e professores formadores, como no episódio transcorrido nos turnos de fala citados acima, constituindo uma ação que vai das teorias às práticas e vice-versa. Nestas interações demarcadas pelo episódio em análise, os licenciandos aprendem com a sistematização de experiências de professores da escola básica e contribuem no processo de reflexão que (re)significa a prática docente desses professores. Assim, também os professores formadores, que igualmente contribuem com essa reflexão, muitas vezes (re)significam a sua prática, ao se enxergarem no relato dos outros do discurso.

Analisando o episódio acima, é possível perceber que a professora primeiramente descreve a prática realizada, mas em certo momento passa a refletir sobre o que aconteceu. Ibiapina (2008) levanta algumas questões que permitem condições, na pesquisa colaborativa, aqui entendida como IA, para o desenvolvimento da reflexão e que estão presentes implícita e explicitamente na medida em que o diálogo avança no episódio analisado. As questões levantadas são: “[...]o que fiz? O que motiva a realizar essas ações? Que conceitos são utilizados? A prática pedagógica serve a que interesse? Como poderia mudar a minha prática? Como posso agir diferente?" (2008, p. 73). Dessa maneira, as perguntas pedagógicas (ALARCÃO, 2010; GÜLLICH, 2013), a narrativa reflexiva e o diálogo formativo são mecanismos de reflexão que possibilitam a sistematização de práticas e facilitam a produção de autonomia docente.

Portanto, quando os professores narram as suas experiências é desencadeada no grupo de formação a reflexão, no momento em que o professor socializa a sua prática e o outro vai se constituindo, bem como ele próprio pela interação com este outro do discurso. A interação que ocorre entre os sujeitos da IFA gera um momento crucial para o desenvolvimento da reflexão crítica. Pois mesmo nos licenciandos que ainda não estão atuando profissionalmente ou envolvidos em bolsas/atividades de iniciação à docência ${ }^{4}$, o ato de ouvir e contextualizar as experiências dos colegas já proporciona um pensamento mais crítico sobre a docência.

A reflexão no processo formativo torna-se mediadora da formação, tanto inicial dos licenciandos, como continuada dos professores da educação básica e professores formadores, colaborando para "[...] mudanças de concepções, como produto de um processo". É deste contexto que depreendemos a expressão professores em formação para todos os sujeitos ativos no processo. Isto se dá especialmente no que se refere ao episódio de sistematização de práticas, através dos relatos de experiência, ou até mesmo dos momentos de formação através do espelhamento das práticas, "[...] em que os movimentos, as diferenças, no diálogo, na reflexão coletiva e compartilhada, fazem fluir a formação" (GÜLLICH, 2013, p. 191).
Acreditamos que na base de uma adequada IFA, que busca na reflexão crítica e na pesquisa da própria ação a produção de saberes docentes, esteja a escrita em diários de formação. Pois a escrita garante o processo de reflexão guiada (pela prática informada) e mediada (pelas discussões e leituras do grupo).

Analisamos as Escritas Narrativas Reflexivas nos diários de formação dos professores em formação e, a partir destas, podemos perceber que, quando os profissionais escrevem nos seus diários de formação, estão analisando, refletindo e transformando a ação docente. "Narrar constitui uma estrutura fundamental na experiência humana" (ARAGÃO, 2011, p. 15), a narrativa constitui o sujeito professor, possibilita expressar seu próprio ponto de vista e explicitar teorias implícitas. Destacamos excertos das escritas narrativas contidas em diários de formação de três Professoras, as quais são sujeitos ativos no coletivo de formação que analisamos desde $2010^{5}$.

Excerto 1: "No dia de hoje o Professor Formador 1 me fez refletir muito, ao colocar sobre os relatos de experiência, sou do quadro de professores há alguns meses e quando fui nomeada todos me assustaram bastante por assumir uma escola "problema", os alunos eram muito marginalizados aos olhos da sociedade em geral, mas percebi que grande parte ao progresso deles dependia do empenho, carinho e atenção dos que estavam a sua volta, todos vinham de famílias fragilizadas e os professores se acomodavam, tinham medo de mudar as atividades rotineiras, onde culpar os alunos pela dispersão, falta de interesse era mais fácil, esquecendo que eles estão numa fase tecnologicamente avançada $e$ querem inovação, mudança. É o que eu busquei resgatar com eles, primeiro criei um ambiente de ensino-aprendizagem favorável, uma troca de saberes e tratei eles, encontrando na fase (idade) deles, com aulas, conversas descontraídas, aulas práticas associadas as teóricas e deixei transparecer a alegria e o amor de ser Professora [...] Meus alunos são meus amigos e juntos trocamos ideias, sorrimos e se há momentos que precisamos ser firmes, não perder o respeito e a postura de ser professor, mas não encontro problemas para ministrar minhas aulas" (Professora 27);

Excerto 6: "A docência demanda um contínuo aprimoramento profissional. E agora é o momento de refletir criticamente sobre as nossas práticas pedagógicas. Devemos romper com o costume regional de usar o livro didático. Hoje tive a constatação de que já ensinei errado. Não é muito agradável essa sensação. [...] temos a oportunidade de trocar experiências com colegas de profissão e área. Já que na minha escola as reuniões de área são ainda muito raras. [...] Na minha prática diária o livro didático é utilizado como pré-roteiro para organizar a aula. O aluno tem uma obra, mas eu utilizo várias. [...] Faço as minhas adaptações" (Professora 9);

Excerto 7: "Ainda não estamos preparados para uma reflexão mais profunda, embasada em teóricos renomados, mas fazemos nossas reflexões diárias, mentais. Talvez a diferença está na escrita, ou falta dela" (Professora 11). 
Acreditamos que os professores que escrevem e refletem sobre as suas ações e práticas no diário de formação conseguem estabelecer mudanças e transformações significativas em seus ensinamentos, buscam sempre melhorar e investigar suas ações e, assim, tornam-se mais autônomos e conscientes sobre suas ações formativas.

No grupo-contexto de trabalho do qual partimos nestas análises, os participantes fazem uso do diário de formação inspirados na proposta de Porlán e Martín (2001). Muitos deles escrevem desde o ano de 2011, como um compromisso de participação no processo de formação. Temos investido no diário como um instrumento de reflexão, tendo em vista que:

[...] o diário é um guia para a reflexão sobre a prática, favorecendo a tomada de consciência do professor sobre seu processo de evolução e sobre seus modelos de referência, favorece também o estabelecimento de conexões significativas entre o conhecimento prático e o conhecimento disciplinar, o que permite a tomada de decisões mais fundamentada (PORLÁN; MARTÍN, 2001, p. 19-20).

No diário o professor expõe, explica, interpreta a sua ação cotidiana da aula ou fora dela, ele faz uma reflexão consigo mesmo acerca de suas práticas (ZABALZA, 1994). As escritas narrativas tornam-se constituintes dos sujeitos professores, pois "[...] o ato da escrita é um encontro conosco e com o mundo que nos cerca" (ALARCÃO, 2010, p. 57). Assim, podemos depreender que a escrita no diário de formação impulsiona uma reflexão crítica sobre as experiências e vivências destes professores, permitindo uma ressignificação nas ações e práticas docentes, a partir do conhecimento de suas ações, de suas concepções. A escrita narrativa vai conferindo ao sujeito, além de guardar a história de sua própria formação, uma reflexão intencionada e deliberada sobre o fazer docente.

Para Güllich, o diário de formação é o "estopim da reflexão", o professor ao escrever "[...] retoma o diálogo formativo do grupo para si e assim, se apropriando do processo de formação, reflete sobre sua ação, investiga-a" (GÜLLICH, 2013, p. 299). Deste modo, finalizamos a análise dos elementos formativos desencadeados no referido projeto, acreditando que é desta forma que os sujeitos se constituem professores, partindo de seus próprios interesses de melhorar a educação. A formação parece carecer de objetos e objetivos comuns, em nossa área percebemos que a pergunta: Por que formação em Ciências? Tem sido um princípio ativo do diálogo e da reflexão. Acreditamos também que esta formação não se dá solitariamente, e sim em um coletivo de sujeitos reunidos para o mesmo fim, com objetivos comuns, necessidades formativas, e muito também quando os professores em formação estão imbuídos de sentimentos como formação, transformação, intervenção, mudança e inovação.

\section{Considerações finais}

Os mecanismos utilizados na formação continuada possibilitam aos professores a pesquisa da própria prática, ao passo que a escrita narrativa reflexiva no diário de formação induz a uma revisão continuada da ação do próprio professor, tornando-o autônomo profissionalmente. $\mathrm{O}$ processo de sistematizar em um coletivo docente permite aos professores refletir criticamente sobre a profissão, tornarem-se também sujeitos ativos do processo de formação.

Percebemos também o processo de formação como possibilidade de pensar uma via de mão dupla (possibilitada pela extensão) que vai do individual ao coletivo, e ainda outra, que vai da Escola para a Universidade, e em ambas um caminho de volta. Nos episódios e turnos apresentados tornaram-se visíveis os benefícios do processo formativo a formação e docência dos participantes da tríade de interação, sejam eles: professores da educação básica, os licenciandos e professores formadores.

Estes mecanismos/elementos formativos: a escrita, o relato e o diálogo, são utilizados como facilitadores do processo de formação na metodologia da sistematização de práticas, e nos levam a compreender como a sistematização torna-se articuladora da reflexão na formação de professores. Permite afirmar que a transformação das práticas pedagógicas vai acontecendo à medida que há uma interação com outros profissionais da área.

Quando a problemática educativa tem assentamento num contexto, este se torna formativo (pesquisa educativa), e assim, os elementos abordados geram e favorecem o desenvolvimento da reflexão sobre, para e na ação. Neste caso, como demonstrado pelos resultados produzidos, há um alargamento do conceito de IA para IFA, como afirmam Alarcão (2010) e Güllich (2013), pois a reflexão é tomada como formativa. Assim, torna-se possível depreender, a partir da produção de resultados de diferentes pesquisas e projetos de ensino e extensão que temos analisado e foram citados neste texto, o potencial da IFA crítica como um caminho em que se vai das práticas às teorias e das teorias às práticas. Portanto, a ideia de abordar, refletir e conceitualizar a experiência profissional torna-se um movimento reflexivo-formativo para o desenvolvimento profissional docente, em especial no que se refere à formação em Ciências.

\section{Contribuição de cada autor}

Ambos os autores participaram de todas as etapas do projeto de extensão e pesquisa, bem como da produção do texto.

\section{Notas}

${ }^{1}$ Este projeto teve início no ano de 2010 e de lá para cá foi desenvolvido em várias versões, dando origem a um programa de extensão: Ciclos Formativos no Ensino de Ciências e Matemática. Já contou com financiamento do MEC pelo Projeto PROEXT e com financiamentos da PROEC - UFFS como projeto de extensão. Atualmente atente a 10 municípios da região das Missões do RS e tem em média 200 participantes ativos, e é financiado pelo projeto do MEC- Ação 20 RJ (SISFOR). 
${ }^{2}$ Este recorte é de um trabalho de pesquisa publicado em Person e Güllich (2013).

${ }^{3}$ Este recorte é de um trabalho de pesquisa publicado em Person e Güllich (2014).

${ }^{4}$ A exemplo do Programa Institucional de Bolsas de Iniciação à Docência (PIBID Ciências, PIBID Ciências Biológicas) e Programa de Educação Tutorial (PETCiências).

${ }^{5}$ Este excerto está discriminado em Person e Güllich (2015b).

\section{Referências}

ALARCÃO, I. Professores reflexivos em uma escola reflexiva. 7.ed. São Paulo: Corteza, 2010.

ARAGÃO, R. M. R. Memórias de formação e docência: bases para a pesquisa narrativa e biográfica. In: CHAVES, Silvia N.; BRITO, Maria R. (Orgs). Formação e docência: perspectivas da pesquisa narrativa e autobiográfica. Belém: CEFUJ, 2011. p. 13-36.

CARR, W.; KEMMIS, S. Teoria crítica de la enseñanza: investigación-acción en la formación del profesorado. Barcelona: Martinez Roca, 1988.

CARVAlHO, A. M. P.; GIL-PÉREZ, D. Formação de professores de ciências. São Paulo: Cortez, 2001.

GÜLLICH, R. I. C. Investigação-Formação-Ação em Ciências: um caminho para reconstruir a relação entre livro didático, o professor e o ensino. Curitiba: Prismas, 2013.

IBIAPINA, I. M. L. M. Pesquisa colaborativa: investigação, formação e produção de conhecimentos. Brasília: Líber Livro, 2008.

KIEREPKA, J. S. N.; GÜLLICH, R. I. C. La formación continua de profesores de ciencias: constitución docente por la narración reflexiva. Revista de Educación en Biología, v. 16, n. 2, p. 56-66, 2013.

KIEREPKA, J. S. N.; GÜLLICH, R. I. C. O desencadeamento do diálogo formativo pelo compartilhamento de narrativas em um contexto colaborativo de formação de professores de Ciências e Biologia. REIEC (Buenos Aires), v. 12, n. 1, p. 55-67, 2016.

MORAES, R. Educar pela pesquisa: exercício de aprender a aprender. In: MORAES, R.; LIMA, V. M. do R. (Orgs.). Pesquisa em sala de aula: tendências para a educação em novos tempos. 3. ed. Porto Alegre: EDIPUCRS, 2012. p. 93-103.

NÓVOA, A. Os professores e a sua formação. Trad. G. Cunha, C. Hespanha, C. Afonso e J. A. S. Tavares. 2. ed. Lisboa: Instituto Inovação Educacional, 1995.

PERSON, V. A.; BOSZKO, C.; GULLICH, R. I. C. A sistematização de práticas pedagógicas na formação continuada de professores de ciências. In: ENCONTRO NACIONAL DE EDUCAÇÃO E CICLOS DE ESTUDOS DA PEDAGOGIA (ENACED), 17, 2015, Santa Rosa. Anais... Santa Rosa: UNIJUÍ, 2015.

PERSON, V. A.; GÜLLICH, R. I. C. O espelhamento de práticas desencadeando a reflexão na formação continuada de professores de Ciências. In: ENCONTRO NACIONAL DE EDUCAÇÃO E CICLO DE ESTUDOS
DA PEDAGoGiA, 16, 2013, Santa Rosa. Anais ... Santa Rosa: Editora UNIJUÍ, 2013.

PERSON, V. A.; GULLICH, R. I. C. O Papel da Sistematização de Experiências como mediador da Formação de Professores In: SEMINÁRIO INTERNACIONAL DE EDUCAÇÃO EM CIÊNCIAS (SINTEC), 3, 2014, Rio Grande. Anais... Rio Grande: FURG, 2014. Disponível em: < http://www.casaleiria.com.br/sintec3/sintec3.htm >

PERSON, V. A.; GÜLliCH, R. I. C. Concepções de ensino e a prática reflexiva na formação continuada de professores de Ciências e Biologia. In: EREBIO SUL, 7, 2015, Criciúma. Anais... Criciúma: Ed. UNESC, 2015a.

PERSON, V. A.; GÜLLICH, R. I. C. Compreendendo a investigação-ação como modelo formativo e a reflexão como um instrumento de constituição de professores. In: CONGRESSO INTERNACIONAL DE EDUCAÇÃO CIENTÍFICA E TECNOLÓGICA (CIECITEC), 3, 2015, Santo Ângelo. Anais... vol. 3, n. 1, Santo Ângelo, 2015 b. Disponível em: < http://www.santoangelo.uri.br/anais /ciecitec/2015/home.htm\#trabalhos >

PERSON, V. A.; GULLICH, R. I. C. Investigação-ação: da extensão à análise de processos formativos de professores de Ciências In: Movimentos Formativos: Caminhos e Perspectivas na Formação de Professores. 1 ed. Cerro Largo: Polimpressos, 2015c. p. 145-166.

PERSON, V. A.; GULLICH, R. I. C. Relatos de Experiências: um meio de investigar e refletir colaborativamente a prática docente em Ciências In: Movimentos Formativos: Caminhos e Perspectivas na Formação de Professores. 1 ed. Cerro Largo: Polimpressos, 2015d, p. 303-312.

PORLÁN, R.; MARTÍN, J. El diario del profesor: un recurso para investigación en el aula. Díada: Sevilla, 2001. SCHÖN, D. La formación de profissionales reflexivos: hacia un nuevo diseño de la enseñanza y el aprendizage en las profesiones. Barcelona: Paidós, 1992.

SILVA, L. H. A.; SCHNETZLER, R. P. Buscando o caminho do meio: a "sala de espelhos" na construção de parcerias entre professores e formadores de professores de Ciências. Ciência \& Educação (Bauru) v. 6, n. 1, p. 4353, 2000.

ZABAlZA, M. A. Diários de aula. Portugal: Porto Editora, 1994.

ZANON, L. B. Interações de licenciandos, formadores e professores na elaboração conceitual de prática docente: módulos triádicos na licenciatura de Química. Tese de Doutoramento, Universidade Metodista de Piracicaba - UNIMEP. Piracicaba, 2003.

Como citar este artigo:

PERSON, V. A.; BREMM, D.; GÜLLICH, R. I. C. A formação continuada de professores de ciências: elementos constitutivos do processo. Revista Brasileira de Extensão Universitária, v. 10, n. 3, p. 141-147, 2019. Disponível em: < https://periodicos.uffs.edu.br/index.php $\underline{\text { RBEU/article/view/10840/pdf }>}$ 